\title{
Design and Implementation of Computer Aided Physical Education Platform Based on Browser/Server Architecture
}

\author{
https://doi.org/10.3991/ijet.v14i15.11146 \\ Zhen Zhao $\left({ }^{\bowtie}\right)$, Jing Yang \\ Beijing institute of petrochemical technology, Beijing, China \\ zhaozhen@bipt.edu.cn
}

\begin{abstract}
Based on the B/S mode network development technology, this paper studies the design and implementation of computer-aided physical education platform. According to requirement analysis of the platform, this study carries out the overall design and detailed design of the platform, compares and analyzes the teaching effects of computer-aided physical education platform and the traditional teaching method. The research results show that: the computer-aided physical education platform runs stably and realizes the expected design functions, it can enrich the teaching content, enhance students' initiative awareness, stimulate their interest in learning, effectively improve the teaching effect, and the paper confirms the feasibility and effectiveness of the system. This research provides a reference for the application of computer-aided physical education platform in physical education and has certain practical significance.
\end{abstract}

Keywords-B/S architecture, computer-aided instruction (CAI), physical education platform

\section{$1 \quad$ Introduction}

The advent of the information age has prompted various industries to carry out computer informatization revolution and constructed their own information network platforms. Driven by the China Education Information and Research Network and the China Education Television Satellite Multimedia Transmission Platform, many teaching subjects have gradually begun to implement CAI, making CAI an important part of modern teaching methods [1]. Physical education is obviously different from other disciplines. Body language teaching is the main feature and requirement of physical education [2], and the particularity of physical education makes the study of computer-aided physical education particularly important.

The CAI platform not only has the storage and running functions of ordinary computers, but also realizes human-computer interaction through the interactive operation of windows and pictures [3]. Cao Xiaodong pointed out in the Discussion on the Reform of College Sports Network Education [4] that a perfect online course system can 
not only ease the teachers' pressure from traditional teaching, but also allow students to have opportunities and platforms to continue their sports learning outside the classroom. Kong Xinliang believes that CAI is an organic and unified process that promotes teaching to become a teacher-led, student-centered teaching activity [5]. Liu Dianguo's research shows that CAI can effectively improve the quality of teaching, which is an important topic for contemporary college PE teachers [6]. The development of computer and network technology has a long history in foreign countries. At present, the use of computers in the United States has reached a status that there's no computer that is not connected [7]. The development of CAI in Britain, America and Singapore is the most advanced, however, its teaching mode only suites the European and American people, and it is not consistent with China's national conditions [8]. Although China's CAI research has made great progress, due to the particularity of physical education, there are still many shortcomings in the theoretical and practical research of computer-aided physical education, and there is still much room for improvement. The B/S structure is a network structure mode after the rise of WEB [9]. In this mode, the core functions of the system are concentrated on the server, which realizes zero installation and zero maintenance of the client-end, the user only needs a computer that is connected to the internet, and it is one of the most widely-used structural modes.

According to above analysis, this paper briefly analyzes the principle and characteristics of the $\mathrm{B} / \mathrm{S}$ structure. Based on the network development technology of $\mathrm{B} / \mathrm{S}$ mode, this study carries out overall design and detailed design of the computer-aided physical education platform, and divides the platform into two major parts: background administrator and user, and 12 sub-modules. Using comparative analysis, it analyzes the difference in the teaching effects of the computer-aided physical education platform and the traditional teaching mode, and verifies the feasibility and effectiveness of the computer-aided physical education platform.

\section{Design and Implementation of Computer-Aided Physical Education Platform Based on B/S Architecture}

\subsection{B/S structure overview}

The B/S (Browser/Server) structure is a three-tier structure improved based on the $\mathrm{C} / \mathrm{S}$ structure [10]. The Server implements most of the transaction logics, and other few are implemented by Browser [11], user only needs a computer that is connected to the internet to use the system functions through the browser, Figure 1 shows the $\mathrm{B} / \mathrm{S}$ three-layer structure. 


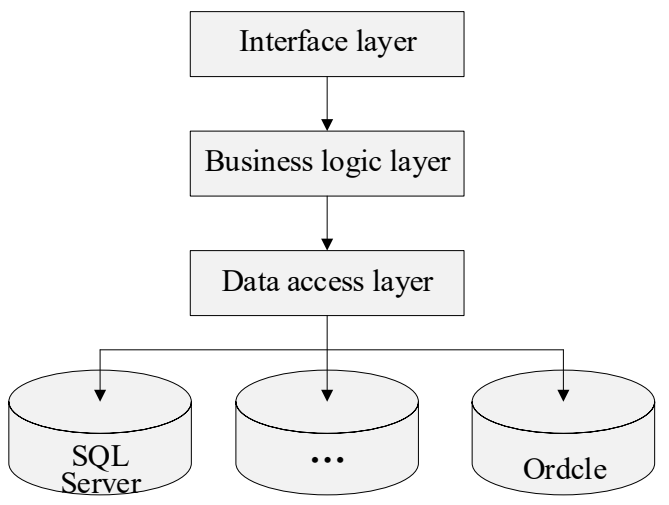

Fig. 1. Overall design architecture of the platform

The advantage of the $\mathrm{B} / \mathrm{S}$ structure is that the user does not need to install any software, which simplifies the problem of the load on the client-end computers, realizes zero maintenance of the client-end, and reduces the maintenance cost of the system [12]. Users can access and operate the shared database through different access methods, and guarantee the security of the service database [13].

\subsection{Overall design of the platform}

Requirement analysis of the platform: The computer-aided physical education teaching platform should enable students to learn and share the teaching resources in their own time in an open network environment, and provide opportunities for teachers and students to interact and communicate. Therefore, the platform should equip teachers (administrators) to upload and update the teaching resources, reply to the messages of students, and students should be able to browse the teaching resources and teaching plans on this plat-form [14].

Overall design of the platform: According to the requirement analysis, the platform is divided into two parts: the background administrator and the user [15]. The background administrator module includes user online Q\&A, user message processing, pictures, videos and other teaching resources uploading, class management information and plan summary [16]. After logging in to the system, users can realize functions such as browsing relevant resources, leaving messages on the website, online Q\&A, etc. Figure 2 shows the overall design of the platform. 


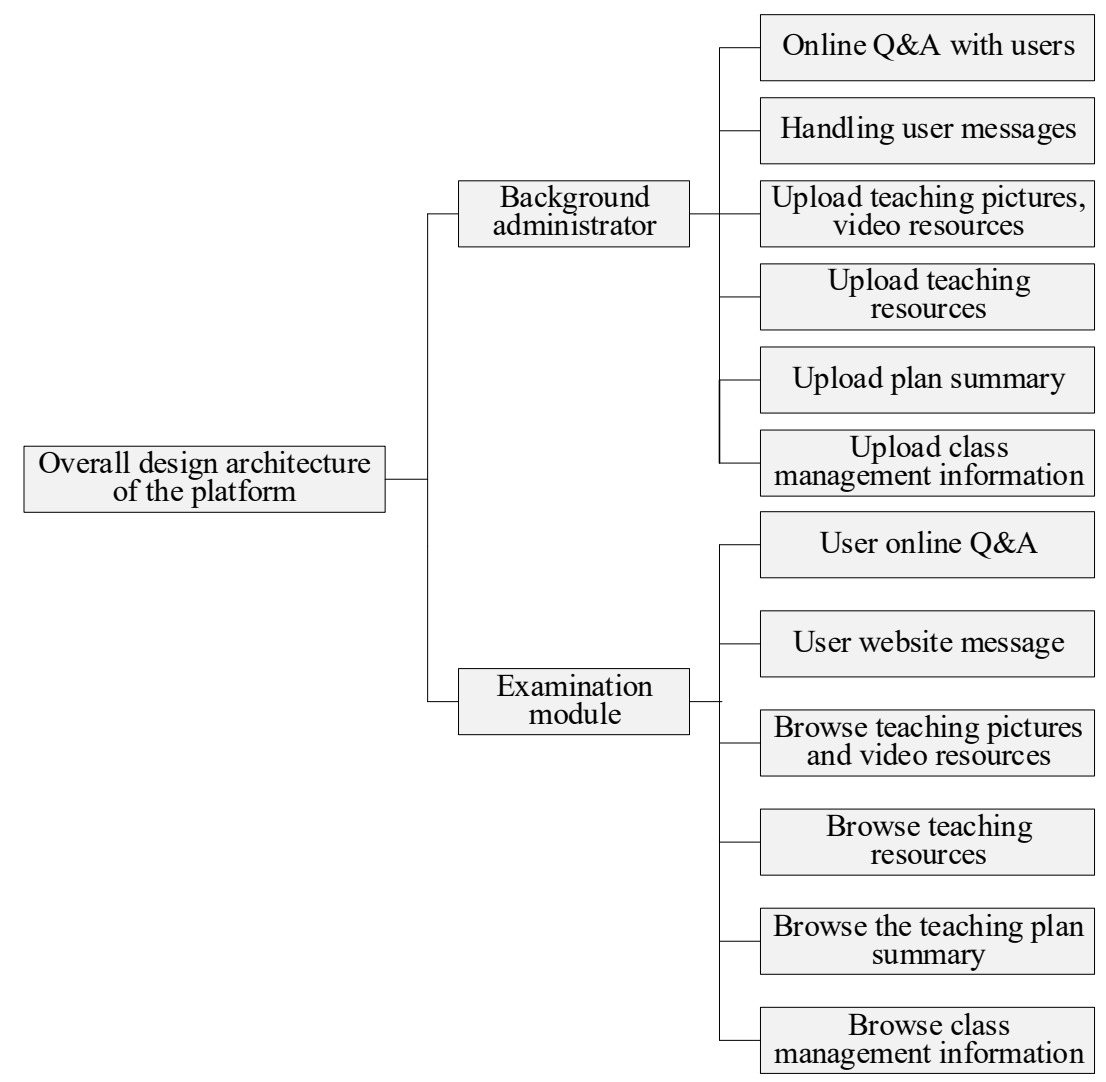

Fig. 2. Overall design architecture of the platform

\subsection{Detailed design and implementation of the platform}

Platform startup page: The startup page of the system should be simple and elegant. In order to ensure the security of the system data, only the registered users can enter the main page of the computer-aided physical education platform and use relevant function modules after entering the correct user name and password on the system login inter-face [17], Figure 3 shows the system login flow chart, Figure 4 shows the startup page of the computer-aided physical education platform. 


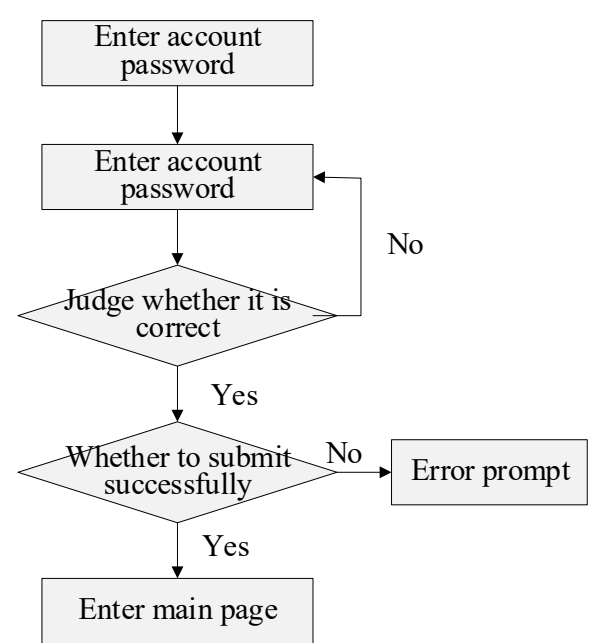

Fig. 3. System login flow chart

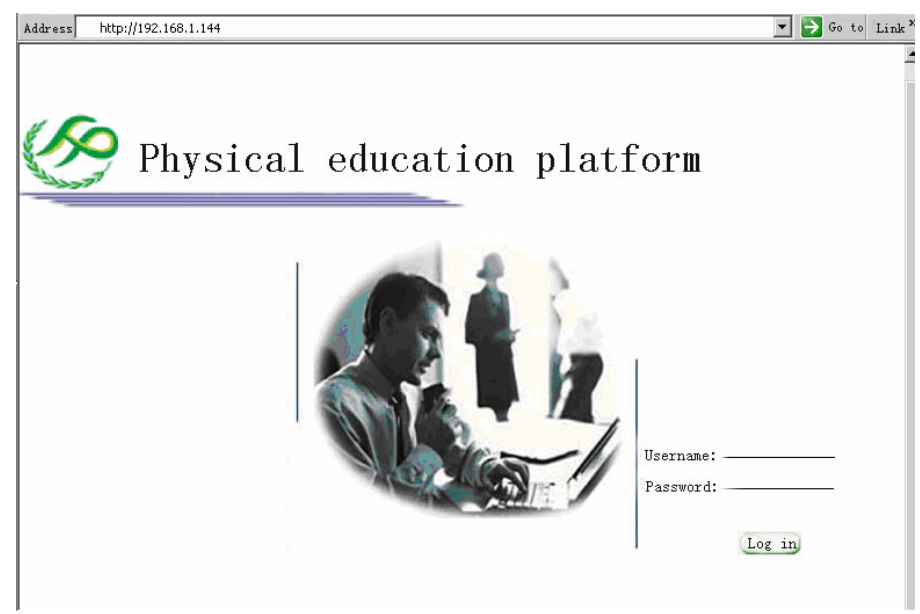

Fig. 4. Startup page of computer-aided physical education platform

Upload teaching resources: After the administrator logs in to the platform, he/she can click the teaching re-source management option, select the address of the resource needs to be uploaded and click importing to realize the uploading of teaching videos, courseware, pictures and other resources, so as to facilitate students' viewing and learning, meanwhile, the system also shows the uploading progress and whether the uploading is successful or not. Table 1 shows use case of teaching resource uploading, and Figure 5 is the teaching resource import interface. 
Table 1. Upload teaching resource use case table

\begin{tabular}{|l|l|}
\hline \multicolumn{1}{|c|}{ Description } & \multicolumn{1}{|c|}{ The administrator logs in to the system and uploads teaching resources. } \\
\hline Participant & System administrator \\
\hline Condition & Login to the system background \\
\hline Result & Upload success or failure \\
\hline Basic process & $\begin{array}{l}\text { 1. Administrator login system } \\
\text { 2. Click on teaching resources } \\
\text { 3. Carry out the teaching resource upload operation } \\
\text { 4. The system returns the result of the operation }\end{array}$ \\
\hline Abnormal & $\begin{array}{l}\text { 1. Login system exception } \\
\text { 2. Operation failed }\end{array}$ \\
\hline Return data & Operation succeeded or failed \\
\hline
\end{tabular}

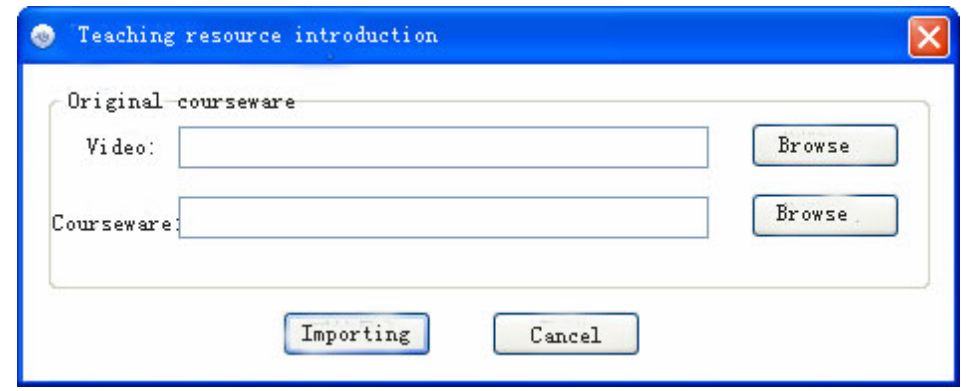

Fig. 5. Teaching resource import interface

User Q\&A: After the administrator logs in to the platform, he/she can select relevant video or image teaching information as needed. Table 2 shows use case of the teaching re-source browsing. Figure 6 shows the volleyball frontal pass-through teaching video that the user has searched for.

Table 2. User online Q\&A use case table

\begin{tabular}{|c|c|}
\hline Description & $\begin{array}{c}\text { After the user logs in to the system, click to view related teaching resources such as } \\
\text { videos and pictures. }\end{array}$ \\
\hline Participant & User \\
\hline Condition & Log in system \\
\hline Result & Upload success or failure \\
\hline $\begin{array}{l}\text { Basic pro- } \\
\text { cess }\end{array}$ & $\begin{array}{l}\text { 1. User login system } \\
\text { 2. Click on a video resource or other related resource } \\
\text { 3. The system feeds back the results. If it succeeds, it will view the related resources, other- } \\
\text { wise the display will fail. }\end{array}$ \\
\hline Abnormal & $\begin{array}{l}\text { 1. Login system exception } \\
\text { 2. Operation failed }\end{array}$ \\
\hline Return data & Teaching resource list \\
\hline
\end{tabular}




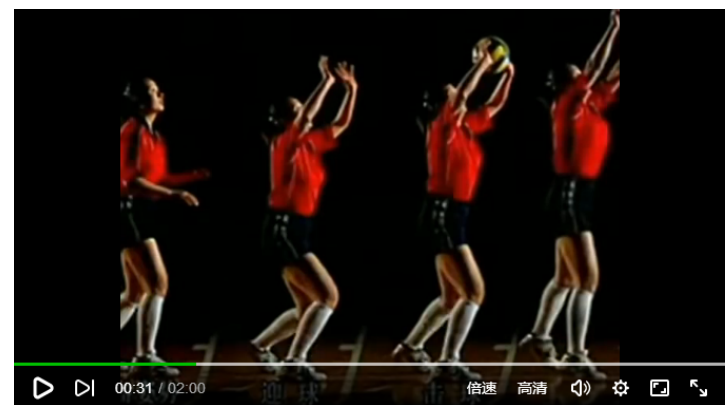

Fig. 6. Volleyball frontal pass teaching video

User Q\&A: The user Q\&A module includes functions such as online Q\&A and asynchronous Q\&A. It can provide teachers and students with a platform for interaction and communication. Students can ask questions in the online chat room, and the online teacher will give timely answers, or if there's no teacher online at that time, students can still view the results after teacher answers the questions. At the same time, according to the questions raised by students, the system will automatically search for related questions in the past, if there's similar questions, the system will automatically answer them, if there's no similar questions, the system will submit it to teachers for answering. Table 3 is the user online Q\&A use case of the platform, and Figure 7 is the online Q\&A interface of the platform.

Table 3. User online Q\&A use case table

\begin{tabular}{|l|l|}
\hline Description & User login to the system for online Q\&A \\
\hline Participant & WEB user \\
\hline Condition & Login to the system \\
\hline Result & Online Q\&A page appears \\
\hline Basic process & $\begin{array}{l}\text { 1. WEB user login system } \\
\text { 2. WEB users click on the online Q\&A } \\
\text { 3. User online Q\&A }\end{array}$ \\
\hline Abnormal & $\begin{array}{l}\text { 1. Login system failed } \\
\text { 2. Q\&A page does not appear }\end{array}$ \\
\hline
\end{tabular}

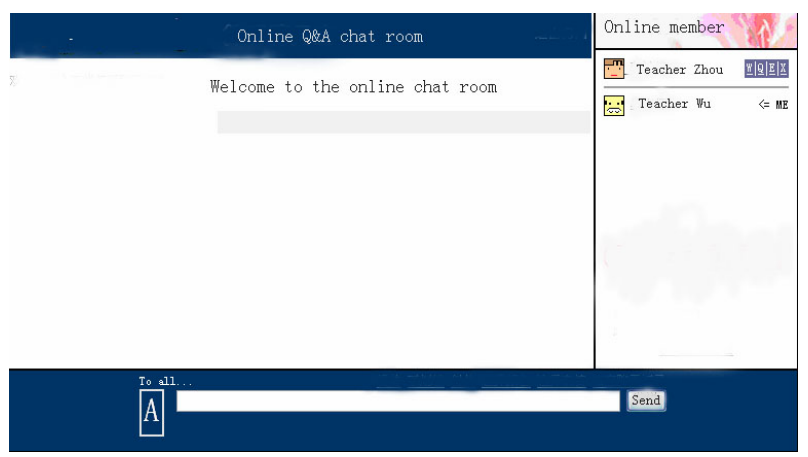

Fig. 7. Online Q\&A interface of the platform 


\section{$3 \quad$ Platform Application and Teaching Effect}

\subsection{Teaching experiment design and implementation}

In order to verify the practical application effect of computer-aided physical education platform, this paper randomly selected two classes of sophomore students from the public sports volleyball elective course of a university, each class had 32 people, one class was taken as the control class, and the other was taken as the experimental class. The traditional teaching method and the computer-aided physical education platform based on B/S architecture were applied for teaching respectively. Except for the teaching methods, other teaching plans were the same, and the test of the basic physical quality indicators of the two classes before the experiment indicated that, for the students of the two classes, there were no significant difference in the indicators.

\subsection{Experimental results}

Student theoretical, technical movement and ball-hitting stability test: After the semester ended, theoretical, technical movement and ball-hitting stability tests were performed on the students of the control class and the experimental class respectively. The theoretical test was carried out through a unified test paper, as for the technical movement and the ball-hitting stability, they were evaluated by a group of three volleyball teachers, and the teachers' rating was taken as the final score, Table 4 shows the comparative analysis results of the control class and the experimental class.

Table 4. Comparative analysis of the results of the control class and the experimental class

\begin{tabular}{|l|l|c|c|c|}
\hline \multicolumn{2}{|c|}{ Category } & Theory & Technical action & Ball-hitting stability \\
\hline \multirow{2}{*}{ Control group } & Average & 13.84 & 30.72 & 31.21 \\
\cline { 2 - 5 } & Standard deviation & 1.9132 & 4.3956 & 4.0207 \\
\hline \multirow{2}{*}{ Test group } & Average & 15.44 & 33.07 & 33.62 \\
\cline { 2 - 5 } & Standard deviation & 2.0793 & 3.4834 & 3.1798 \\
\hline \multirow{2}{*}{ Average difference } & 1.6 & 2.35 & 2.41 \\
\hline \multirow{2}{*}{$\mathrm{P}$} & 3.103 & 2.3050 & 2.5648 \\
\hline $\mathrm{P}$ & $<0.05$ & $<0.05$ & $<0.05$ \\
\hline
\end{tabular}

It can be seen from the table that the three results of the control class and the experimental class are significantly different $(\mathrm{p}<0.05)$, and the scores of the experimental class students are significantly better than the control class.

Analysis of the questionnaire after the experiment: Figure 8 is an investigation of the learning interest of the experimental class students in the computer-aided physical education platform teaching method, Figure 9 shows whether the students in the experimental class have strengthened their communication with the teacher on the network teaching system. The results show that, about $93 \%$ of the students said that this kind of teaching method can improve their interest in learning, and through the proposed teaching method, they can better master the volleyball technical movements, which is convenient for their self-study after the class, and at the same time, $84.4 \%$ of 
the students said that it enhances the communication between teachers and students, which is conducive to improving learning efficiency, therefore, $89 \%$ of students are very satisfied with this teaching method. Basically, all students hope to learn in this way of teaching in their future physical education.

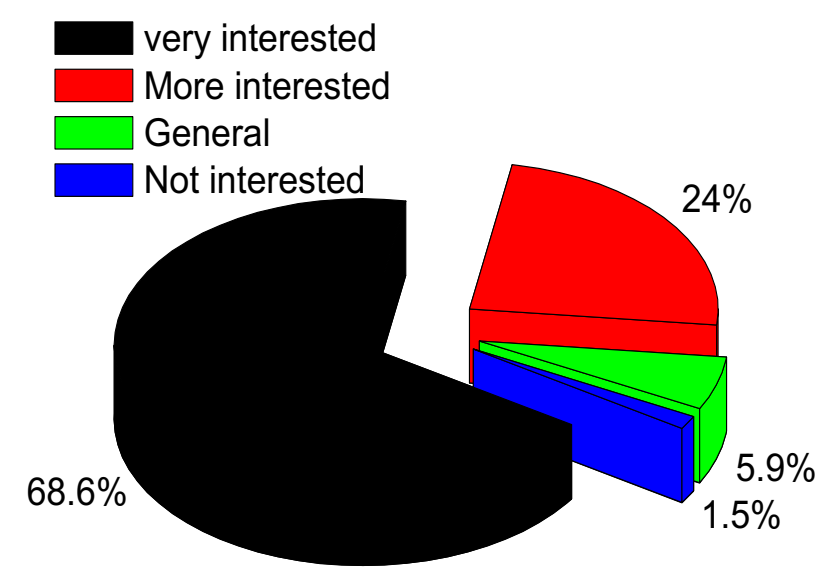

Fig. 8. Learning interest survey

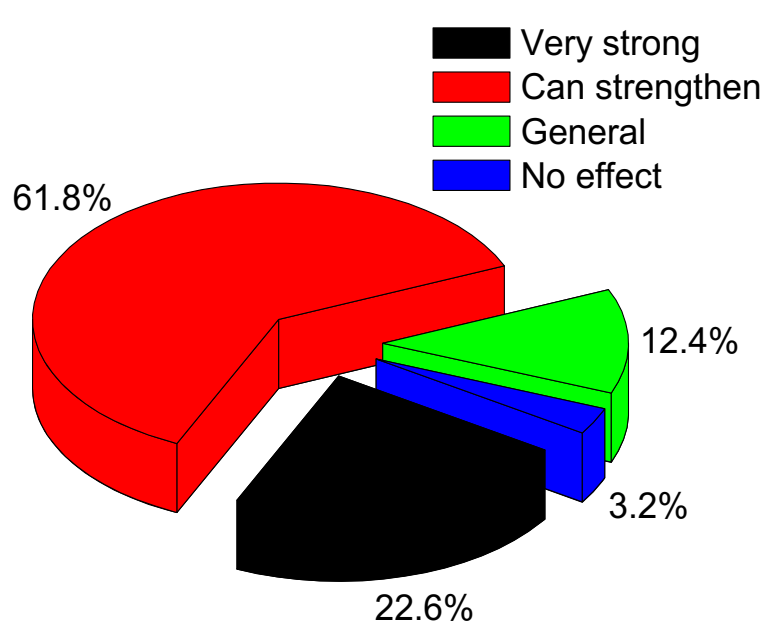

Fig. 9. Does the network teaching system strengthen communication with teachers?

Figure 10 shows the students' requirements and opinions on the video materials used in the teaching platform. It can be seen from the figure that most students think that when learning through the computer-aided physical education platform, not only the detailed learning and instruction videos are needed, but students should be able to choose the learning content and control the playback progress according to their requirements, and freeze the video if necessary. 


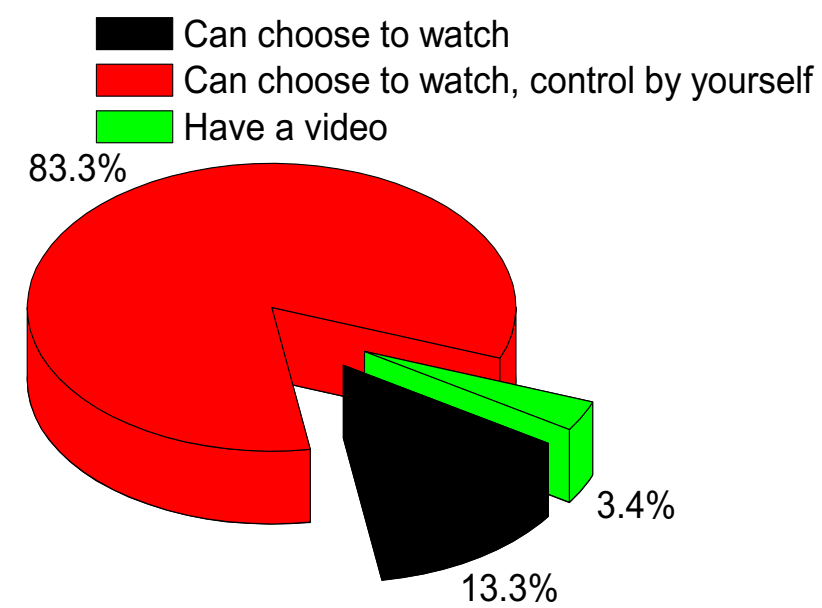

Fig. 10.Students' requirements and opinions on the video materials used in the teaching platform

\subsection{Analysis of experimental results}

Through the analysis of the experimental results of the computer-aided physical education platform and the traditional teaching mode, it can be seen that the application of the platform transforms the role of the teachers from the knowledge indoctrinator to the learning guide for students, teachers can make use of the advantages of the platform to assist in explaining knowledge points that students can hardly understand or are hard to be expressed through language, so that teachers can understand and master the situation of students, and implement different education according to the students' own situation. In addition, the platform also strengthens the communication between teachers and students, and this kind of communication can prompt teachers to constantly adjust, update and promote the teaching process. Through the learning scenario created by the teacher, the students become the subject of learning and the discoverer of knowledge, their passive learning converts into active exploration, which greatly enhances the students' enthusiasm for learning.

The computer-aided physical education platform can stimulate students' senses through intuitive technical movement videos and vivid teaching pictures, combining with the teachers' explanations, it can effectively improve the teaching effect of physical education, therefore, this platform has certain feasibility and effectiveness.

\section{Conclusion}

The rapid development and wide popularization of computer networks have made the CAI modes widely applied in the field of education. This paper studied the design and implementation of computer-aided physical education platform. The specific conclusions are as follows: 
- Based on the network development technology of B/S mode, the overall design of the computer-aided physical education platform was divided into two parts: background administrator and user, and 12 sub-modules.

- Taking the platform startup page, teaching resource uploading and user Q\&A as examples, detailed design of the platform was conducted and implemented.

- This paper conducted comparative analysis on the teaching effects of computeraided physical education platform and the traditional teaching mode, the results showed that the computer-aided physical education platform can stimulate students' interest in learning and effectively improve the teaching effect.

\section{$5 \quad$ References}

[1] Keating, X. (2003). The current often implemented fitness tests in physical education programs: problems and future directions. Quest, 55(2): 141-160. https://doi.org/10.1080/0033 $\underline{6297.2003 .10491796}$

[2] Sun, H., Chen, A. (2010). A pedagogical understanding of the self-determination theory in physical education. Quest, 62(4): 364-384. https://doi.org/10.1080/00336297.2010.10483 $\underline{655}$

[3] Carlson, T.B., Hastie, P.A. (1997). The student social system within sport education. Journal of Teaching in Physical Education, 16(2): 176-195. https://doi.org/10.1123/jtpe.16.2. $\underline{176}$

[4] Henderson, B., Camorlinga, S., Degagne, J. C. (2004). A cost-effective web-based teaching file system. Journal of Digital Imaging, 17(2): 87-91. https://doi.org/10.1007/s10278004-1001-y

[5] Woolf, B.P., Hall, W. (1995). Multimedia pedagogues: interactive systems for teaching and learning. Computer, 28(5): 74-80. https://doi.org/10.1109/2.384121

[6] Almohammadi, K., Hagras, H., Yao, B., Alzahrani, A., Alghazzawi, D., Aldabbagh, G. (2017). A type-2 fuzzy logic recommendation system for adaptive teaching. Soft Computing, 21(4): 965-979. https://doi.org/10.1007/s00500-015-1826-y

[7] Kumar, B., Kumari, C., Sharada, M., Mangala, M. (2012). Evaluation of the medical records system in an upcoming teaching hospital-a project for improvisation. Journal of Medical Systems, 36(4): 2171-2175. https://doi.org/10.1007/s10916-011-9681-6

[8] Kirk, D., Macdonald, D. (1998). Situated learning in physical education. Journal of Teaching in Physical Education, 17(3): 376-387. https://doi.org/10.1123/jtpe.17.3.376

[9] Liu, J., Fu, R. (2018). Development of an accounting skills simulation practice system based on the B/S architecture, International Journal of Emerging Technologies in Learning, 13(10): 134-145. https://doi.org/10.3991/ijet.v13i10.9459

[10] Paschal, Cynthia, B. (2002). Formative assessment in physiology teaching using a wireless classroom communication system. Advances in Physiology Education, 26(4): 299-308. https://doi.org/10.1152/advan.00030.2002

[11] Chatzisarantis, N., Hagger, M., Biddle, S., Smith, B., Wang, J. (2003). A meta-analysis of perceived locus of causality in exercise, sport, and physical education contexts. Journal of Sport \& Exercise Psychology, 25(3): 284-306. https://doi.org/10.1123/jsep.25.3.284

[12] Li, W., Wang, W., Zhao, Y. (2013). Research and development on survey and statistical analysis software of resident travel od based on b/s mode. Procedia - Social and Behavioral Sciences, 96: 1453-1459. https://doi.org/10.1016/j.sbspro.2013.08.165 
[13] Bailey, R. (2010). Physical education and sport in schools: a review of benefits and outcomes. Journal of School Health, 76(8): 397-401. https://doi.org/10.1111/j.17461561.2006.00132.x

[14] Papastergiou, M. (2009). Exploring the potential of computer and video games for health and physical education: a literature review. Computers \& Education, 53(3): 603-622. https://doi.org/10.1016/j.compedu.2009.04.001

[15] Souza, R.P., Pinheiro, T., Magalhaes, A.L.C.C., Mesquita, R.C. (1998). An object-oriented platform for teaching finite element pre-processor programming and design techniques. IEEE Transactions on Magnetics, 34(5): 3407-3410. https://doi.org/10.1109/20.717802

[16] Balas, C.E., ErgiN, A., Williams, A.T., Koc, L. (2004). Marine litter prediction by artificial intelligence. Marine Pollution Bulletin, 48(5-6): 449-457. https://doi.org/10.1016/j.marpol bul.2003.08.020

[17] Charles, X., Corey, S., Jie, C., Saeid, N., Joyce, M. (2018). Learning and teaching engineering design through modeling and simulation on a cad platform. Computer Applications in Engineering Education, 26(4): 824-840. https://doi.org/10.1002/cae.21920

\section{Authors}

Zhen Zhao graduated from capital institute of physical education in 2002, received his bachelor's degree in sports training, and graduated from Liaoning normal university sports institute in 2010, have a master's degree in sports. He worked currently in Beijing institute of petrochemical industry, and mainly engaged in sports teaching, training and research title lecturer. In 2017, he edited and published the "guidance course for college students' extracurricular sports activities", and won the second prize in the 19th sports science paper report conference of capital universities in 2018.

Jing Yang graduated from Beijing sports university in 2001, received his bachelor's degree in physical education, and she graduated from Beijing normal university sports institute in 2010, have a master's degree in sports. She worked currently in Beijing institute of petrochemical industry, and mainly engaged in sports teaching, training and research title lecturer. In 2014, she was funded by the young talents project of Beijing municipal education commission, and in 2018, she won the second prize of the 19th sports science paper report conference of capital universities.

Article submitted 2019-05-29. Resubmitted 2019-07-05. Final acceptance 2019-07-05. Final version published as submitted by the authors. 